\title{
Información parlamentaria autonómica en la Red: un impulso electrónico a la democracia
}

\author{
Por Mari Carmen Marcos y Ana Belén Gil
}

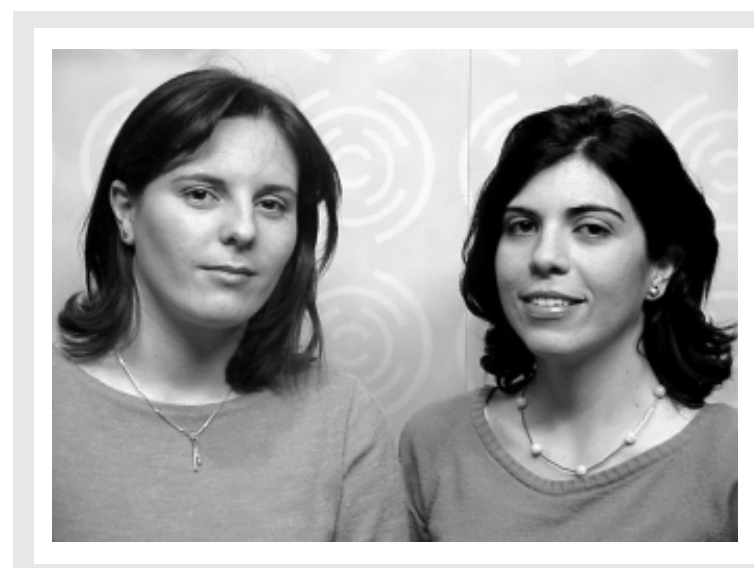

Resumen: Se analiza la información que ofrecen los sitios web parlamentarios de las comunidades autónomas españolas a finales del año 2001 tomando como punto de partida las pautas aprobadas por el Consejo Interparlamentario en su sesión de Amman en el año 2000 y adaptándolas a las peculiaridades de las autonomías españolas.

Palabras clave: Sitios web parlamentarios, Contenidos web, Democracia parlamentaria, Comunidades autónomas, España.

Title: Parliamentary information on the Net: promoting democracy electronically

Abstract: The present study analyses the information contained in the parliamentary web sites of Spain's autonomous regions, as of December 2001. The analysis was performed using guidelines approved by the Interparliamentary Council in Amman in 2000, and adapted to the specific situations of the 16 Spanish regional autonomies.

Keywords: Parliamentary web sites, Web contents, Parliamentary democracy, Autonomous regions, Spain.

Marcos, Mari Carmen; Gil, Ana Belén. "Información parlamentaria autonómica en la Red: un impulso electrónico a la democracia". En: El profesional de la información, 2002, marzo-abril, v. 11, n. 2, pp. 91-101.

Las nuevas tecnologías juegan un papel muy importante en la difusión de información; en este estudio vamos a considerar en concreto el que cumplen en el aspecto político (más concretamente parlamentario) de los países. Partimos de que el sistema democrático debe garantizar la transparencia de los procesos legislativos de manera que el ciudadano tenga la posibilidad de ejercer un control sobre la política de su nación y creemos que la web cumple los requisitos idóneos para lograr ese objetivo: puede tener un alcance global a todos los puntos del país y a todas las personas interesadas, permite la comunicación mediante texto, imágenes y sonidos, posee medios para la interacción con el ciudadano (chats, foros, e-mail). En este estudio pretendemos dar a conocer hasta qué punto los parlamentos de nuestras comunidades autónomas - los órganos legislativos más cercanos a los ciudadanos- recurren a internet para difundir una información que nos afecta a todos.

\section{Transparencia e internet}

El artículo 9.2 de la Constitución Española indica que "corresponde a los poderes públicos [...] facilitar la participación de todos los ciudadanos en la vida política, económica, cultural y social”. El primer texto normativo que refleja la importancia de las redes telemáticas para la relación con la Administración es la Ley de Régimen Jurídico de las Administraciones Públicas y el Procedimiento Administrativo Común (Ley 30/1992 de 26 de noviembre), que contempla la posibilidad de habilitar los cauces de comunicación informática entre el administrado y las distintas administraciones. Posteriormente el Real Decreto 263/1996, de 16 de febrero, ampliaba el artículo 45 de la citada ley regulando la utilización de técnicas electrónicas, informáticas y telemáticas por la Administración General del Estado. En ese mismo año, la Orden de 15 de febrero regulaba la composición y funcionamiento de la Comisión Ministerial de Tecnologías de la Información y de las Comunicaciones, poco después modificada por una Orden de 26 de diciembre.

Así como existe regulación sobre el uso de las nuevas tecnologías en la Administración, todavía no la hay en el ámbito parlamentario, si bien los distintos órganos legislativos centrales y autonómicos están poniendo el máximo interés en difundir la información al 
ciudadano. El punto de inicio de esta tendencia está en el Senado, que en 1998 creó la Comisión de Redes Informáticas con el objetivo de estudiar las repercusiones políticas, sociales y económicas del uso de internet, así como para promocionar las ventajas y oportunidades que ofrece el desarrollo tecnológico.

\section{«El Senado creó en 1998 una Comisión de Redes Informáti- cas con el objetivo de estudiar las repercusiones políticas, so- ciales y económicas del uso de internet»}

Con todo el material recogido se elaboró un informe que fue aprobado por unanimidad en el pleno celebrado el 17 de diciembre de 1999. Como colofón, se recogen catorce resoluciones sobre internet en las que se tratan temas diversos como el derecho a la información, a la intimidad, a la educación; los contenidos en español; el libre comercio; las infraestructuras; la propiedad intelectual; etc. La última conclusión es la que más atañe al tema que tratamos en este trabajo: "las instituciones parlamentarias utilizarán las redes electrónicas para aproximar las relaciones entre representantes y representados, facilitando la participación activa y directa de los españoles en sus actividades y procedimientos".

\section{Ciudadano rico, ciudadano pobre}

Las grandes ventajas del uso de las nuevas tecnologías nos lleva a pensar en la gran desventaja que van a sufrir aquellas personas que no dispongan de acceso a la Red, ya sea por no contar con los medios económicos para comprar equipos informáticos, falta de disponibilidad de conexión en su zona geográfica, no tener la formación necesaria para manejarse o por problemas de discapacidad física o sensorial que afecte al uso habitual de los ordenadores. Por estos y otros mo-

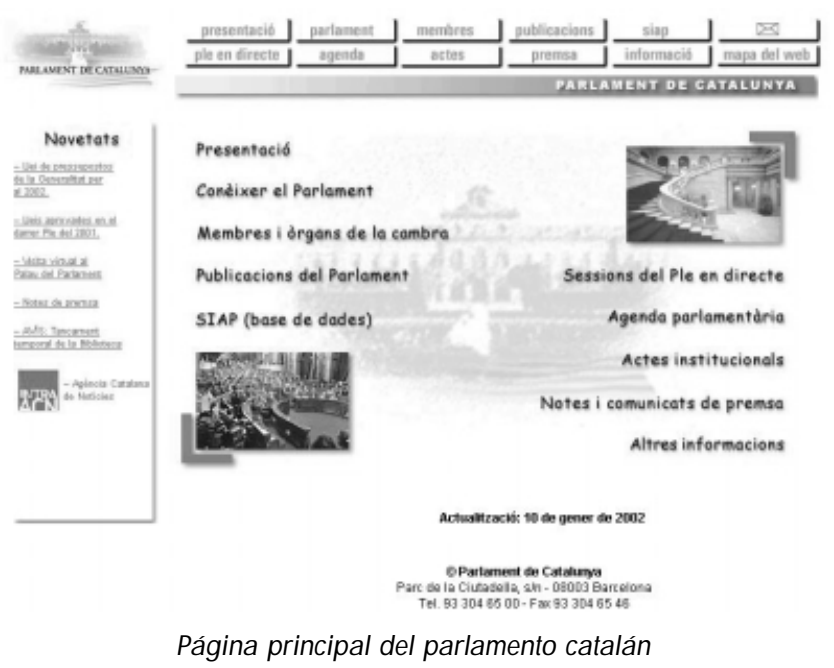

Parlamento de Andalucía:

http://www.parlamento-and.es

Cortes de Aragón:

http://www.cortesaragon.es

Junta General del Principado de Asturias:

http://www.jgpa.es

Parlament de les Illes Balears:

http://www.parlamentib.es

Parlamento de Canarias:

http://www.parcan.rcanaria.es

Parlamento de Cantabria:

http://www.parlamento-cantabria.es

Cortes de Castilla-La Mancha:

http://www.cortesclm.es

Cortes de Castilla y León:

http://www.ccyl.es

Parlament de Catalunya:

http://www.parlament-cat.es/porta.htm

Asamblea de Extremadura:

http://www.asambleaex.es

Parlamento de Galicia:

http://www.parlamentodegalicia.es

Asamblea de Madrid:

http://www.asambleamadrid.es

Asamblea Regional de Murcia:

http://www.asambleamurcia.es

Parlamento de Navarra:

http://www.parlamento-navarra.es

Eusko Legebiltzarra-Parlamento Vasco:

http://parlamento.euskadi.net

\section{Corts Valencianes: \\ ttp://www.corts.gva.es}

tivos se está creando ya una sociedad culta en internet y otra inculta. La repercusión de estas diferencias en la posibilidad de acceso a las páginas web de los parlamentos puede llegar a ser tan fuerte que se esté favoreciendo a los grupos "cultos" y dejando a un lado a los "incultos".

El informe redactado por la comisión del Senado indica en uno de sus puntos que "la universalización del acceso a la información por parte de los ciudadanos aparece como una necesidad, un servicio y un derecho que los poderes públicos deben garantizar, aus- 
piciar y proteger [...]. La obligación de los legisladores españoles consiste ahora en diseñar los mecanismos para poner al servicio de la inmensa mayoría de ciudadanos las ventajas, los avances y los progresos que las nuevas tecnologías de la información ofrecen o pueden ofrecer [...]. Es una responsabilidad de los legisladores y del gobierno central y de los de las comunidades autónomas garantizar la igualdad de oportunidades a los ciudadanos y a los territorios del Estado".

\section{Análisis de las sedes web}

El estudio realizado por la Unión Interparlamentaria (UIP) y presentado en el consejo celebrado en Amman (Jordania) en el año 2000 revela que a principios de abril el 57\% de los parlamentos nacionales disponía de página web, un total de 101 países. El objetivo de dicho estudio era analizar los sitios parlamentarios para conocer su estructura y contenido, para lo cual se plantearon unos elementos mínimos que deberían contemplar. La UIP no tuvo en cuenta otras instituciones parlamentarias que no fueran las nacionales, por lo que al tomar sus pautas hemos tenido que adaptarlas a los casos de las autonomías españolas y además hemos querido ahondar de manera más especial en aquellos aspectos que favorecen de forma di-

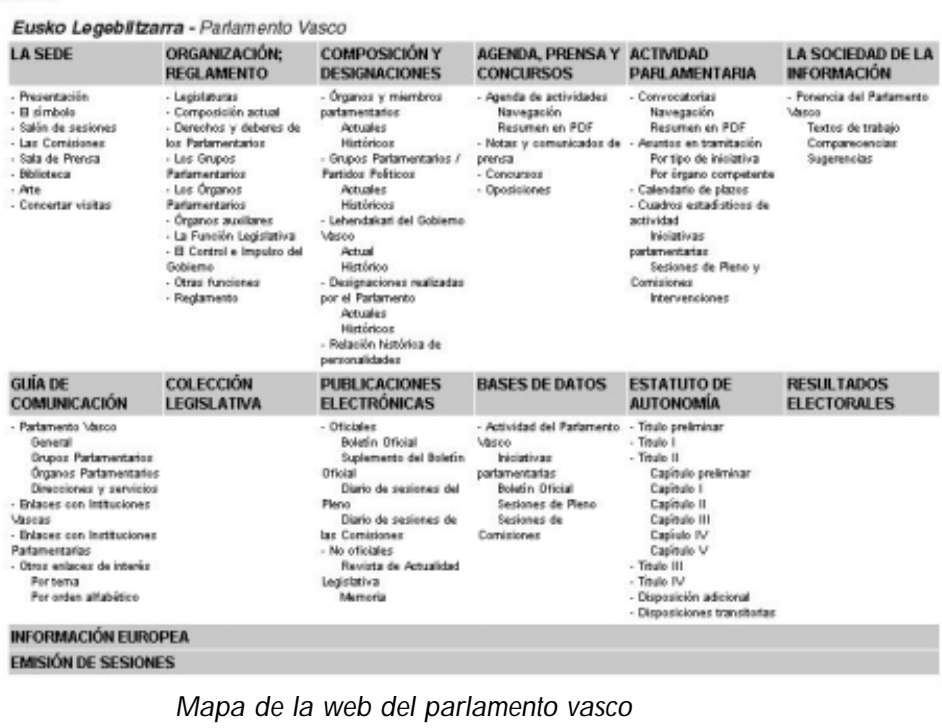

recta en la participación ciudadana y democracia parlamentaria.

En nuestro país tanto el Congreso como el Senado cuentan con páginas web desde hace años. En cambio algunos parlamentos autonómicos han tardado un poco más en subirse al carro de las comunicaciones. A fecha de hoy sólo falta la presencia de La Rioja. La página del Senado puede considerarse pionera en la introducción del concepto de participación de los internautas en nuestro país con un foro de discusión en el que intervienen ciudadanos y senadores.

Se exponen a continuación los resultados obtenidos del análisis de las páginas web de los parlamentos de

\section{Bases de dâtos}

"La documentación interna debe estar vinculada a la gestión de la propia actividad parlamentaria mediante sistemas informáticos [...] y que esta fuente de información o base de datos sirva para el control de la actividad corriente [...]" Mateo Maciá (1993).

En la actualidad está implantada en los parlamentos autonómicos la utilización de bases de datos para gestionar grandes cantidades de información y documentación. Sin embargo, estas herramientas no se encuentran siempre a disposición del público a través de la página web. En este sentido, debemos resaltar que algunos de estos organismos han entendido el cauce electrónico para hacer accesible la actividad desarrollada en sus cámaras. De esta forma, los siguientes parlamentos han instalado bases de datos en sus páginas de acceso público y con estos contenidos:

- Iniciativas parlamentarias: País Vasco, A ragón, $N$ avarra (referencial), Canarias, Baleares, Cataluña, A ndalucía y próximamente la Comunidad Valenciana.

- Leyes: País Vasco, Comunidad Valenciana (Legista recoge las de todas las comunidades y las estatales desde 1993), Aragón, Asturias y Cataluña.

- Publicaciones: País Vasco, Aragón, N avarra, Asturias y Cataluña.

- Asuntos en tramitación: País Vasco, Aragón, Baleares (referencial) y C ataluña.

En resumen, los parlamentos vasco, catalán y aragonés son los que ofrecen mayores posibilidades al ciudadano ya que hacen accesible la información contenida en sus bases referente a iniciativas parlamentarias, textos legislativos, asuntos en tramitación y publicaciones. Destacamos la inclusión de pautas y ayudas que complementan el formulario de búsqueda del documento en cuestión, así como las distintas opciones para interrogar al sistema (legislatura, fecha, proponente, órgano, situación, etc., y por supuesto texto). 
las comunidades autónomas españolas a finales del año 2001. Hemos centrado la atención en tres aspectos: tución,

-información que se ofrece sobre la propia insti-

- elementos que fomentan la participación ciudadana en la vida parlamentaria, y

—herramientas que favorecen la accesibilidad a la información.

\section{a. Elementos informativos.}

La UIP establece los apartados informativos que deben contener las páginas. A grandes rasgos son: información general sobre la estructura del parlamento; sistema electoral y grupos políticos; procesos y documentos legislativos; el presidente y los vicepresidentes; miembros del parlamento; órganos parlamentarios y publicaciones. Creemos conveniente introducir en este punto la consulta de bases de datos de iniciativas, sean o no legislativas, así como las publicaciones de la cámara.

1. Información de tipo general en una visión de conjunto. Nos referimos a aquella de naturaleza práctica referida a la dirección de la sede del parlamento, cómo llegar hasta él, la inclusión de un mapa de situación, etc. Estos datos son muy útiles para el ciudadano que quiera visitar el edificio o asistir a algún acto del parlamento, o simplemente dirigirse por correo postal o electrónico para solicitar información. A pesar de ello no aparecen tanto, ni tan claramente, como cabría esperar. En ocasiones su dirección se encuentra en secciones como "directorio" (p. e. Extremadura), y más frecuentemente en un apartado dedicado a informar sobre visitas a la sede. Se echa en falta la agrupación de estas informaciones en la página de inicio. Destacamos el Parlamento de Baleares y la Asamblea de Madrid como buen ejemplo.

Se ha considerado también información general la que incluye historia del edificio y de la institución, funciones del parlamento, actualidad e información

\section{Democràcia.web}

Portal promovido por la Fundació Jaume Bofill que tiene como objetivo favorecer la información, el debate y la participación ciudadana a través de la Red. Para ello impulsa la utilización de internet como medio de comunicación entre los ciudadanos y sus representantes políticos. A través de Parlament on line los grupos parlamentarios catalanes pueden conocer la opinión de su ciudadanía sobre proyectos y proposiciones de ley durante la tramitación parlamentaria.

http://www.democraciaweb.org

\section{Parlament 0 bert}

Iniciativa de la Universitat Oberta de Catalunya que muestra las posibilidades de participación de los ciudadanos en las instituciones públicas a través de internet. Mantiene un espacio denominado La llei a debat que está destinado al seguimiento de la tramitación parlamentaria de los proyectos de ley en Cataluña y sus correspondientes discusiones, así como a la participación de los ciudadanos en dichos procesos mediante su opinión.

http://www.uoc.es/parlamentobert

variada sobre concursos, contrataciones, anuncios y actividades no parlamentarias. Sobre estos contenidos hay que resaltar que casi todas las sedes ven reflejada su descripción histórica y artística en mayor o menor medida. Este hecho es el resultado de la tendencia de recuperación de inmuebles históricos para la instalación de órganos parlamentarios. Incluso en casos de instalaciones modernas se proporciona información sobre sus características arquitectónicas. Es el caso de las Asambleas de Murcia y Madrid.

\section{«Es una responsabilidad de los legisladores y, del gobierno central y de los gobiernos de las comunidades autónomas garantizar la igualdad de opor- tunidades a los ciudadanos y a los territorios del Estado»}

La explicación de las funciones del parlamento se integra en secciones generales que describen de forma más o menos divulgativa los objetivos y la justificación de su existencia. El Parlamento de Baleares lo denomina muy significativamente "qué es, qué hace". Todos los casos contienen esta información en sus sitios webs y resulta coherente con la intención de aproximarse al ciudadano de forma que se conozca la institución y sus cometidos.

También se ha considerado la presencia de un espacio de información de actualidad sobre la institución y su proyección hacia el exterior conformado por notas de prensa, comunicados y/o noticias parlamentarias. En este sentido cobra importancia el apartado de anuncios y novedades, que puede incluir desde avisos sobre servicios hasta convocatorias de becas y concursos (p. e. Aragón), además de jornadas y actos culturales. Más de la mitad de las webs estudiadas tienen un apartado propio para recoger estos datos, e incluso algunas optan por colocarlos en la página de inicio.

Dentro de la información general, la mayoría incluye los textos normativos del Parlamento, principal- 
mente el reglamento y el estatuto de autonomía. Para ambas disposiciones se ofrecen dos alternativas: su colocación independiente en la página (Extremadura) o su inclusión en apartados como "funciones y normas" (Canarias), "leyes" (Castilla-La Mancha), "legislación institucional" (Cataluña) o "símbolos" (Aragón). En cambio, sólo Baleares, Cantabria y Cataluña ofrecen el texto de la Constitución Española.

Valoramos positivamente la unión de los datos mencionados, a ser posible accesibles desde la página de inicio, ya que el ciudadano puede beneficiarse de su lectura para buscar una primera aproximación al Parlamento como institución, conocerlo someramente y adquirir datos prácticos para su visita o consulta.

\section{«A principios de abril de 2000 el $57 \%$ de los parlamentos na- cionales disponía de página web, un total de 101 países»}

2. Sobre el sistema electoral y los últimos resultados. Los datos electorales reflejan la voluntad política de los ciudadanos. De hecho la mayoría de los parlamentos autonómicos ha querido aportar información sobre algún aspecto relacionado con las últimas elecciones. Aproximadamente la mitad los ofrecen por partidos y el mismo número de parlamentos presenta un gráfico representativo de la composición de la cámara. En cambio, apenas se han planteado describir el propio procedimiento electoral ni ofrecer la ley. Sólo Castilla-La Mancha ofrece ambas informaciones. Baleares opta por enlazar con una página de "resultados electorales" que por el momento no se encuentra disponible. Hay que destacar el enlace que se hace desde el Parlamento Vasco a una página del gobierno de la comunidad centrada en el tema electoral, donde se muestra amplia información sobre los últimos comicios autonómicos y en la que se quiere implantar dentro de un tiempo el voto electrónico.

\section{Elvil (European legislative virtual hibrary)}

Proyecto desarrollado por la Universidad de Estocolmo, la Universitat Oberta de Catalunya y la M onfort University del Reino U nido. D esde su página web se accede a:

- biblioteca virtual, con entrada a bases de datos parlamentarias y a un índice de leyes;

- centro de formación sobre legislación y política; $y$

- centro cívico donde los ciudadanos pueden comunicarse con las organizaciones y los representantes de la política.

http://www.uoc.es/elvil/prototype3/home/home.html

\section{Parlamento Virtual peruano}

En Perú se han creado varias iniciativas para que el Congreso esté a disposición de los ciudadanos. Éste en concreto es un sistema interactivo para la comunicación del pueblo con la política. A demás existe un programa de radio - Punto de encuentro con el Congreso (también accesible en internet en formato MP3)-. Se permite el acceso a su sistema de votación electrónica y a la Gaceta del Congreso con las sesiones de las comisiones y los plenos, que se puede recibir por correo electrónico; se ofrece también un archivo digital de legislación peruana y otro de proyectos de ley que permite conocer el estado de tramitación de las iniciativas.

http://www.congreso.gob.pe/index.htm

3. El proceso legislativo: proposiciones de ley, proyectos de ley y leyes aprobadas. Es la función por antonomasia del parlamento, por tanto es lógico que todas las webs presenten información sobre el trabajo legislativo y en bastantes casos se describa el proceso con la suficiente claridad y afán de transmitirlo a la ciudadanía. Suele incluirse en apartados denominados "funciones, funcionamiento, normas", y así aparece en once de las páginas que más detallan este proceso. Hay que señalar la intención divulgativa plasmada en epígrafes del tipo "cómo se hace una ley" en el Parlamento de Navarra, que se ha incluido en "historia y funciones", o la colocación de su apartado global en un lugar destacado de la página de inicio, como disponen en las cortes aragonesas en "conozca cuál es la función de las Cortes de Aragón".

A este respecto se ha considerado muy valiosa la información aportada sobre los textos legislativos en tramitación y el grado en que la proporcionan los diez parlamentos que recogen estos trabajos parlamentarios. Los casos más sobresalientes son Cataluña, Canarias, Aragón y País Vasco, que presentan al ciudadano la posibilidad de buscar estas iniciativas legislativas en bases de datos. Otros como Baleares, Cantabria, Navarra, Castilla y León muestran un listado con el detalle de la tramitación y la referencia del boletín de publicación. En cambio Valencia y Andalucía incluyen sólo el texto de la iniciativa.

En cuanto a los textos ya aprobados, en algunas ocasiones encontramos apartados donde se listan todas las leyes de la comunidad autónoma de la que se trate (Madrid, Galicia, Murcia) con alguna información como el boletín oficial donde se publicaron (es el caso de Baleares), o la posibilidad de acceder a su texto en ese mismo apartado en formato pdf o html, como ocurre en Castilla-La Mancha, Andalucía y Castilla y León entre otros.

El profesional de la información, vol. 11, nํ2, marzo-abril 2002 


\section{Baremo empleado en la evaluación}

\section{a. Elementos informativos.}

\section{Información general:}

- Localización física de la sede: dirección postal $50 \%$, plano de situación $50 \%$.

- Historia edificio e institucional: $50 \%$ cada una.

- Funciones parlamento: explicación detallada $100 \%$.

- Textos normativos: estatuto de autonomía $50 \%$, reglamento $50 \%$.

- Actualidad: noticias de prensa $75 \%$, otros anuncios $25 \%$.

\section{Elecciones:}

- Descripción procedimiento: breve $25 \%$, extensa $50 \%$, con ley electoral $100 \%$.

- Resultados: numéricos $75 \%$, gráfico $25 \%$.

\section{Procedimiento legislativo:}

- Descripción procedimiento: explicación detallada $100 \%$.

- Agenda parlamentaria: sin orden del día $50 \%$, con orden del día $100 \%$.

- Seguimiento de la tramitación: información somera $25 \%$, listado de iniciativas $50 \%$, base de datos referencial $75 \%$, base de datos a texto completo $100 \%$.

- Leyes aprobadas: información somera $25 \%$, listado referencial 50\%, listado con acceso al texto completo $75 \%$, base de datos a texto completo $100 \%$.

\section{Órganos parlamentarios:}

- Presidente: datos biográfi$\cos 25 \%$, funciones $75 \%$.

- Miembros: $25 \%$ por cada listado (alfabético, por grupos parlamentarios, por circunscripción electoral), $25 \%$ si se detalla su pertenencia a comisiones.

\section{Publicaciones:}

- P. oficiales: información somera $25 \%$, consulta en línea $50 \%$, búsqueda por fecha o número $75 \%$, base de datos con búsqueda por texto $100 \%$.

-P. no oficiales: información somera $25 \%$, listado $50 \%$, listado con mayor detalle $75 \%$, acceso web a texto completo a alguna de ellas $100 \%$.

\section{Enlaces:}

- Congreso y Senado 25\%

-0 tros parlamentos de ccaa $25 \%$.

- Parlamento Europeo 25\%.

- 0 tros parlamentos extranjeros $25 \%$.

\section{b. Participación ciudadana.}

\section{Activa:}

- Correo-e y buzón de consultas: $50 \%$ y $100 \%$ respectivamente.
- Correo-e de servicios, órganos, diputados y grupos parlamentarios: $25 \%$ cada uno.

- Foros de debate: enlace a página externa $50 \%$, existente pero inactivo de momento $75 \%$, activo $100 \%$.

\section{Pasiva:} $100 \%$.

- Retransmisión de plenos

- Información sobre asistencia a plenos $100 \%$.

- Información sobre visitas a sede y parlamento $100 \%$. $100 \%$

- Visita virtual $100 \%$.

- Espacio infantil y/o juvenil

c. Accesibilidad. No se ha tenido en cuenta la consideración hacia discapacitados ni las faqs debido a su mínima existencia en el tiempo de hacer esta evaluación.

- 0 tras lenguas: presentación o saludo $25 \%$, contenido parcial $50 \%$, web bilingüe en su totalidad $75 \%$, web completamente trilingüe $100 \%$.

- Correo webmaster $100 \%$.

- Buscador 100\%.

- Menús y/o guías de navegación $100 \%$.

- Fecha de actualización en lugar visible $100 \%$.
En esta línea merece la pena destacar la creación de bases de datos con este contenido que ofrecen mayores posibilidades de búsqueda e informativas; ocurre con las Cortes de Aragón, la Junta del Principado de Asturias, el Parlamento de Cataluña, el Parlamento Vasco y las Cortes Valencianas. En total son doce los parlamentos que ofrecen en sus páginas al menos un listado de las leyes aprobadas en la última legislatura.

En cuanto al trabajo parlamentario, la mayoría de los sitios web ponen a disposición del ciudadano la agenda con los actos previstos (comisiones y plenos fundamentalmente), pero no todos incluyen además el orden del día donde se detallen los contenidos que se tratarán en cada reunión. Algunas que sí lo hacen son Andalucía, Aragón, Baleares, Canarias, Cantabria,
Castilla-La Mancha, Cataluña, Madrid, País Vasco y Valencia.

4. Información sobre el presidente, los miembros del parlamento y los órganos parlamentarios. Prácticamente todas las webs recogen información sobre la figura del presidente; en su mayoría la incluyen dentro del apartado que describe a los órganos parlamentarios, pero casi ninguna ha dispuesto un apartado independiente para agruparla (sólo Baleares, CastillaLa Mancha y Madrid). Más bien aparece desperdigada en diversos sitios, por ejemplo desde la página de saludo o en las referentes a la Mesa, a la organización del parlamento o a las funciones. De todos modos es muy frecuente que en alguno de estos lugares se dedique un espacio a su biografía y sus funciones pero no se pre- 
senta su agenda de actividades, siendo raro encontrar alguno de los discursos. Ocurre algo similar con los vicepresidentes aunque en este caso la información, más escasa todavía, suele venir junto con la de los miembros de la Mesa o en el listado de diputados que componen la cámara.

Por otra parte, siempre se proporciona los nombres de los miembros parlamentarios por grupos, y en su mayoría también por orden alfabético. La tercera presentación resulta de la circunscripción electoral. Así se detalla en la mitad de los casos estudiados. Además, desde estos mismos listados suele aportarse información de su pertenencia a comisiones y algunos datos biográficos, su trayectoria política, e incluso sus intervenciones en la actual legislatura. Esta última cuestión la observamos en el País Vasco, que la presenta en forma de ficha.

Los parlamentos que más información ofrecen según lo estudiado son el andaluz, el aragonés, el vasco, el valenciano y el castellano-leonés. Éste último recoge las variaciones de diputados ocurridas durante la legislatura en sus páginas web, rasgo que comparte con otros parlamentos.

En conjunto, son más de la mitad (un 75\%) las webs que contienen todos estos temas relacionados con sus miembros, aunque algunas los localicen en otros apartados. Esto ocurre comúnmente con el dato sobre pertenencia a comisiones que puede aparecer en "organización", "órganos", "funcionamiento", como disponen Asturias, Baleares, Extremadura, Madrid, Murcia y Navarra.

Podemos considerar, a la vista de los resultados, que es un tipo de información que se ha cuidado con detalle en la mayoría de las páginas y que resulta también común encontrarla en parecido grado de profundidad con similares características de presentación.

5. Publicaciones. El contenido de las publicaciones oficiales resulta de gran interés para el ciudadano
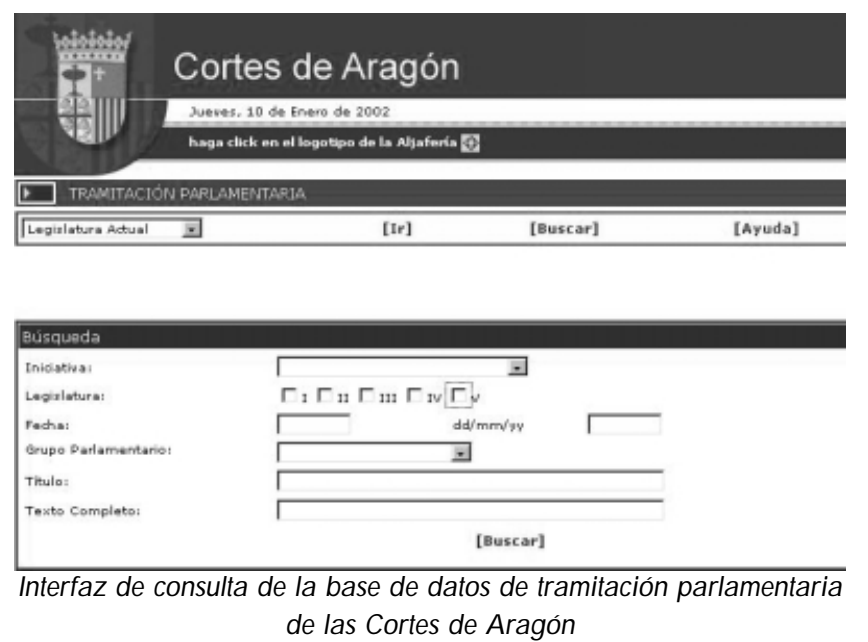

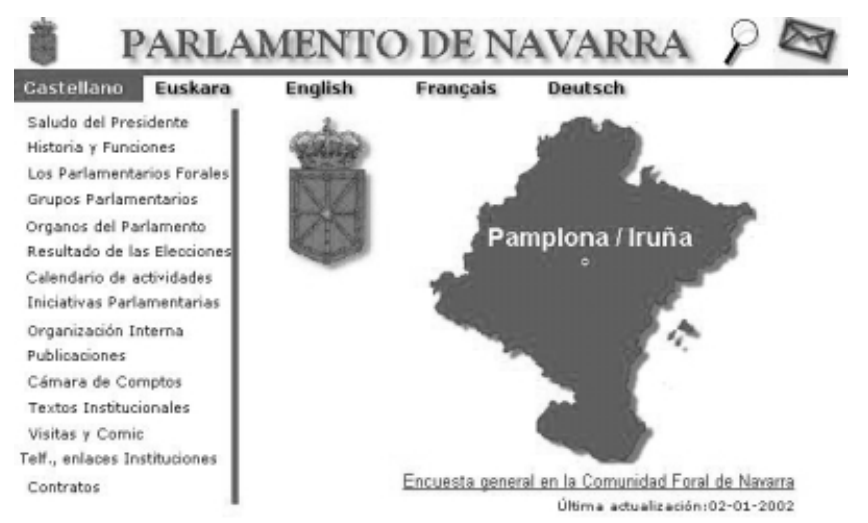

Página de inicio del parlamento navarro con opción de cinco idiomas

de cada comunidad. En trece de los parlamentos visitados se pueden consultar en línea a texto completo. Es posible buscar por número de publicación (boletín oficial o diario de sesiones) en todos los casos y por fecha en la mayoría; sólo en Aragón, Asturias, Cataluña, Navarra y País Vasco funciona la búsqueda por texto en una base de datos. El Parlamento de Galicia vincula a una dirección de correo electrónico para informarse sobre su adquisición.

\section{«Los parlamentos de Cataluña, Andalucía, Canarias, las Cortes de Aragón y el Parlamento Vas- co presentan al ciudadano la posibilidad de buscar las inicia- tivas legislativas en bases de datos»}

Apuntaremos también que bajo este epígrafe se contemplan algunas ediciones publicadas por los parlamentos pero distintas de las procedentes del trabajo parlamentario. Destaca el caso de Andalucía que incluye el catálogo de publicaciones de la institución y el listado de las disponibles en página web. En Baleares pueden descargarse también pliegos y folletos, mientras que en Castilla-La Mancha dan noticia de las publicaciones no oficiales y folletos divulgativos e incluyen sus portadas, igual que Cataluña, aunque ésta no incorpora imágenes. Los parlamentos valenciano y vasco son responsables de la edición de revistas que también ponen a disposición del usuario en su página web, Corts: anuario de derecho parlamentario y $R e$ vista de actualidad legislativa respectivamente.

6. Enlaces externos a diversas fuentes. Se ha valorado que se sitúen en un apartado propio, circunstancia que ocurre en la mayoría de los casos. No obstante también es cierto que es más costoso enlazar con webs de partidos políticos y con el gobierno de la comunidad autónoma de la que se trate, por lo laberíntico de su localización. Lo ideal sería que todas las páginas vinculadas se recogieran en una sección de enlaces, in- 
dependientemente de que se acceda también desde otro lugar de la web.

De esta forma se llega al gobierno de la comunidad en trece de los parlamentos, vinculando con su página principal, y en ocasiones también con cada uno de sus departamentos. En cambio son nueve los que posibilitan el enlace con grupos políticos de ámbito autonómico o nacionales; sólo el aragonés y el catalán lo hacen con ambos, y en el caso de Andalucía únicamente con el grupo parlamentario socialista, que posee web propia y oficina virtual.

Además de estos dos aspectos, se ha considerado relevante la inclusión de direcciones web del resto de parlamentos autonómicos, así como la presencia de las del Congreso y del Senado (ambas posibilidades aparecen en doce de las páginas analizadas). En cuanto a vínculos con el Parlamento Europeo, lo tienen en cuenta diez, y solamente Baleares, Canarias, Cantabria, Cataluña y el País Vasco aportan direcciones de parlamentos de países europeos, y en algunos casos también latinoamericanos.

\section{«Además de los listados de miembros parlamentarios, sue- le aportarse información de su pertenencia a comisiones y al- gunos datos biográficos»}

Otra intención que se ha valorado positivamente es la inclusión, en las autonomías que lo contemplan, de las direcciones de las instituciones vinculadas al parlamento en cada caso. Así, el catalán enlaza con la Sindicatura de Cuentas y el Síndic de Greuges (defensor del pueblo); el Vasco, con el Ararteko y el Tribunal Vasco de Cuentas; el Navarro con la Cámara de Comptos; el de Castilla y León con el Procurador del Común; el de Canarias con el Diputado del Común y la Audiencia de Cuentas; y el de Andalucía con el Defensor del Pueblo y con la Cámara de Cuentas. Resulta pues un aspecto abordado en seis de los ocho casos que pudieran considerarlo.

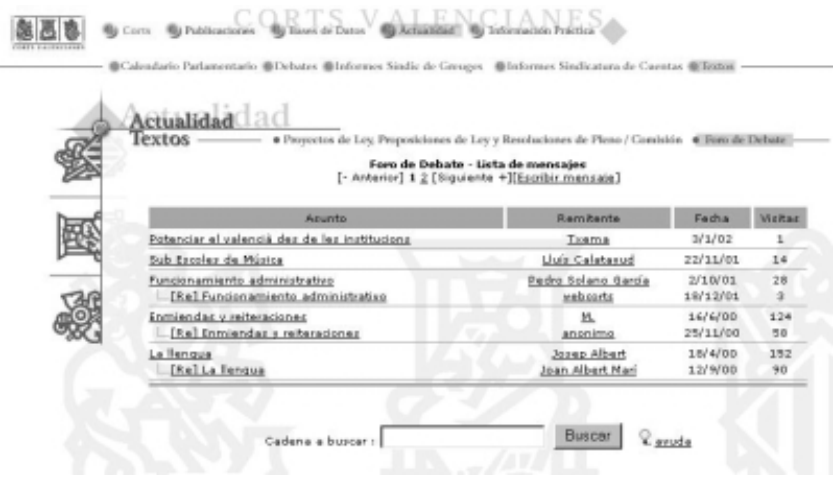

En las cortes valencianas existe un foro para la participación de los ciudadanos

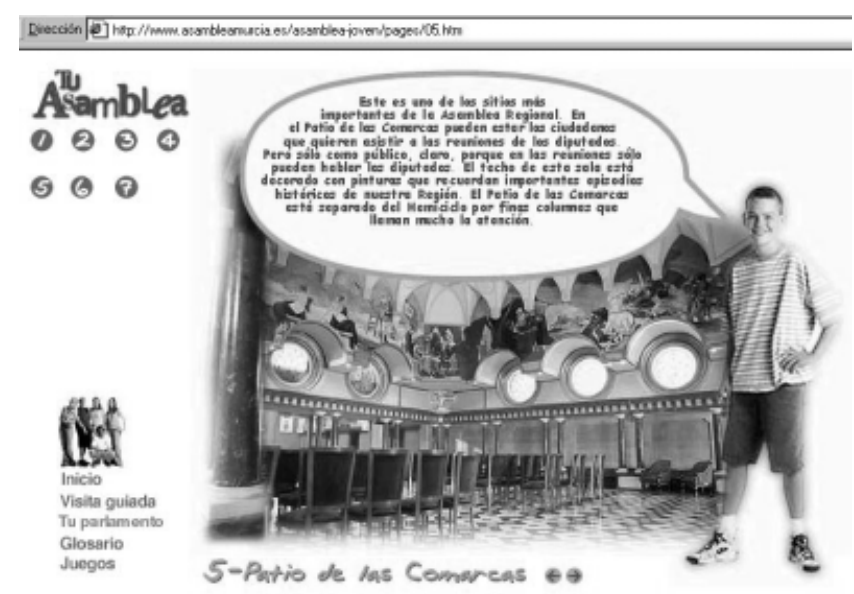

La A samblea de Murcia dispone de páginas para jóvenes

Por último, y aunque existen vínculos también a ONGs, medios de comunicación, gobierno y ministerios, sindicatos, universidades, etc., queremos destacar la inclusión de direcciones de buscadores en las webs de Andalucía, Cantabria, Castilla y León, y Valencia.

\section{Elementos de participación del ciudadano.}

Algunos dispositivos favorecen la posibilidad de que un usuario establezca contacto con el parlamento a través de sus páginas. Este apartado es de gran importancia porque fomenta uno de los principales objetivos de las páginas web parlamentarias, que es la democracia participativa. Para el estudio hemos considerado dos formas de interacción, una activa en la que el ciudadano toma contacto con las cortes y expresa sus ideas o formula sus consultas, y otra que podemos ver más pasiva y que consiste en que el usuario recibe información sobre el desarrollo parlamentario.

Respecto a la participación activa, se cumplen las expectativas casi en un 50\%, ya que la mayoría de los sitios web cuentan con algún medio para fomentar esta comunicación, pero no con todos los recursos que serían deseables. Las comunidades que por el momento ofrecen más facilidades son Baleares, Cantabria, Navarra, País Vasco y Valencia. Dentro de este apartado se ha dado importancia a la existencia de foros de debate, buzones de consultas y sugerencias así como direcciones de correo postal y electrónico en un lugar visible, tanto de los órganos de la cámara como de los distintos servicios e incluso el de los grupos parlamentarios y los diputados.

De una manera menos activa, pero igualmente importante, algunos parlamentos ofrecen medios de participación ciudadana como la retransmisión de los plenos en directo a través de internet, por el momento disponible en Cataluña y en el País Vasco, a punto en Aragón y ya anunciado en Cantabria. La mayoría proporciona información sobre cómo visitar la sede y asistir a los plenos, y algunos han aprovechado las posibilidades de la tecnología para ofrecer recorridos vir- 
tuales (Andalucía, Asturias, Baleares, Cantabria, Cataluña y Valencia). También se ha previsto en algunas webs una sección para niños y jóvenes en la que se explica de forma sencilla la labor del parlamento: en Madrid, Navarra y Valencia lo hacen utilizando el cómic, y en breve Aragón lanzará una animación y actividades. La asamblea que más ha trabajado en este tema es Murcia, que cuenta con unas páginas especiales que incluyen una sección con clara función didáctica accesible sólo para profesores. La idea de incorporar un glosario de términos comunes parlamentarios ha sido tenida en cuenta hasta el mo-

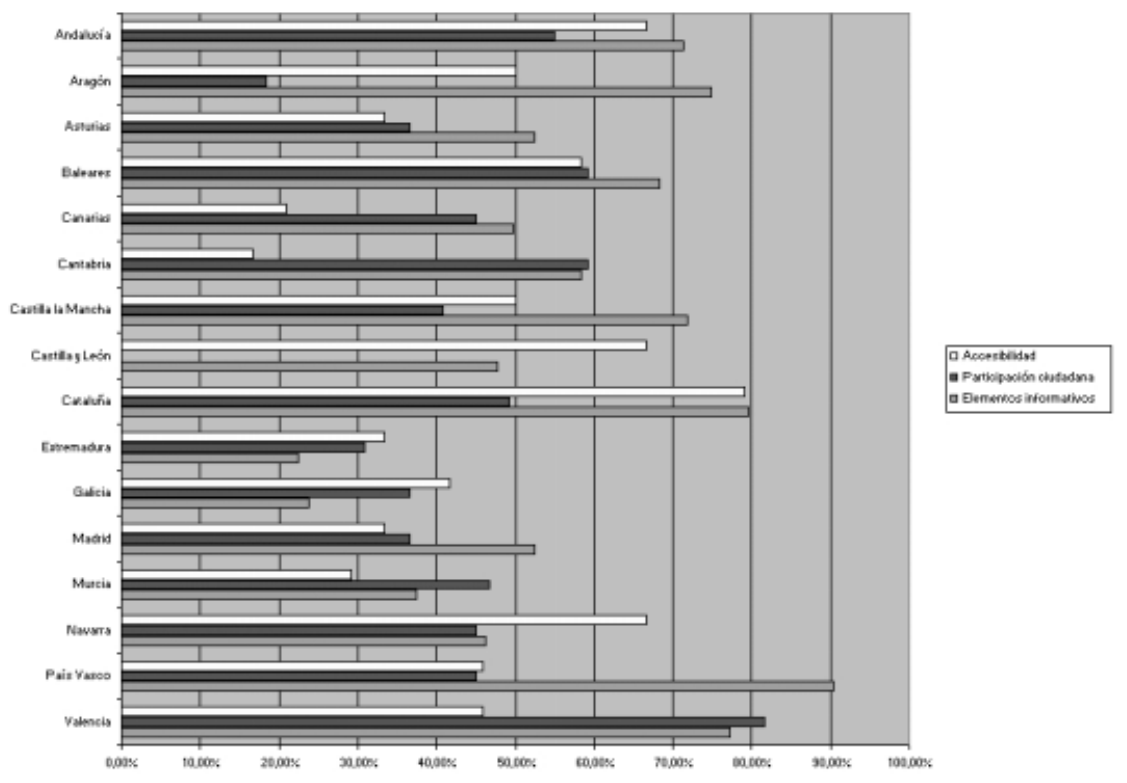
mento en pocos casos: Baleares en su "Parlamento abierto", Cantabria y Murcia.

gina no carga o si lo hace mal, si no se localiza deter-

Toda esta información dirigida a la participación ciudadana, si bien comienza a considerarse cada vez en más sedes web, por el momento no figura en una sección específica, sino que aparece dispersa en distintos apartados. Baleares, Cantabria y Murcia son los primeros que la han creado.

\section{Elementos que favorecen la accesibilidad a la información.}

El estudio de la UIP tiene en cuenta en su análisis los factores de interacción que proporcionan las páginas web. Nosotros consideramos imprescindible para llegar al ciudadano que las herramientas de navegación sean de uso sencillo y proporcionen la información de la forma más fácil posible. Recogemos los aspectos que creemos que más influyen en dicho objetivo.

La dirección de contacto del webmaster es necesaria tanto para hacer consultas sobre la web —si una pá-

Evaluación global

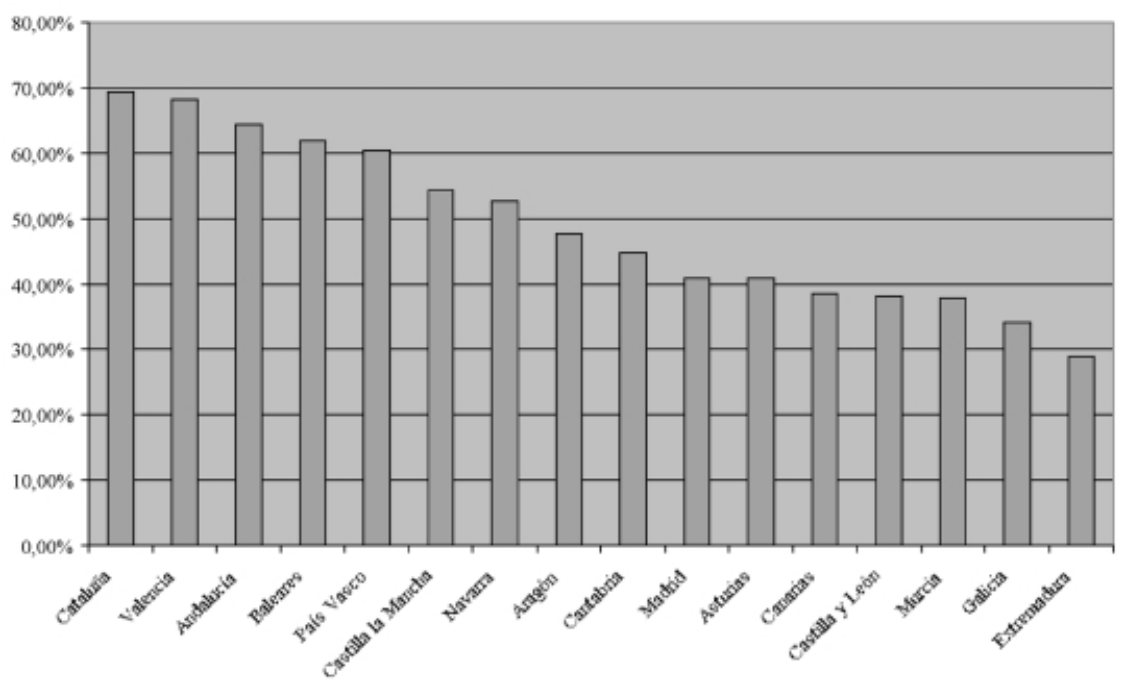
minada información-, como para sugerir innovaciones tanto en su contenido como en la presentación.

No menos importantes resultan las aplicaciones de búsqueda dentro de la web. Con esta denominación nos referimos a la existencia de mapa y de buscador interno. En relación con lo primero, la mitad de las sedes parlamentarias han preparado uno pero en algunas de ellas resulta más útil porque se ha organizado la información con más lógica; buenos ejemplos son Andalucía, Aragón, Cataluña y País Vasco. Con respecto al buscador interno hay que decir que es menos habitual encontrarlo. De hecho sólo Andalucía, Baleares, Navarra y Valencia disponen de él.

También es importante que existan menús y guías de navegación que permitan al usuario ir de unas páginas a otras sin perder el hilo de su camino, es decir, que se mantenga siempre un menú en el mismo sitio para poder acudir a él cuando se quiera cambiar de sección o que exista la posibilidad de retroceder a la página de inicio directamente sin recurrir al propio icono del navegador. Este tipo de herramientas está presente en casi todas las páginas de una forma $u$ otra. Destacamos la web de Baleares por su comodidad en cuanto a este aspecto.

La recomendación de la UIP de disponer de un apartado para preguntas frecuentes (faq) sólo ha sido adoptada por el momento en la comunidad de Baleares. Con el tiempo es posible que algún otro parlamento decida incorporar esta información a su página web. 
Es recomendable que además de la lengua oficial del país se ofrezca la información en otra ampliamente conocida (por ejemplo en inglés). Murcia y Valencia ya disponen de esta traducción, pero es Navarra quien ofrece más perspectivas de acceso con su web completa en inglés, alemán y francés además de las dos lenguas oficiales en su comunidad. Galicia ha previsto esta opción pero por el momento permanece inactiva. La UIP aconseja que las comunidades bilingües reflejen esta característica disponiendo toda la información en ambas lenguas. Así lo han hecho Navarra, País Vasco y Valencia, y en parte Baleares, Cataluña y Galicia. Cataluña destaca por la gran cantidad de idiomas que ofrece ya que, además del catalán, incorpora parte de la información en español, euskera, gallego y aranés (dialecto del valle de Arán).

\section{«La página del Senado puede considerarse pionera en la in- troducción del concepto de participación de los internautas en nuestro país»}

Un aspecto importante que indica la UIP pero que en cambio no hemos observado detenidamente por considerar que su estudio puede resultar muy subjetivo, es la accesibilidad técnica entendiendo por ésta que las páginas se puedan descargar fácilmente con navegadores de versiones anteriores, que no contengan elementos como marcos, imágenes o sonidos que ralenticen el proceso de visualización de la información. Este tipo de análisis requeriría hacer pruebas en distintos equipos informáticos conectados de diversas formas y con navegadores de diferentes versiones para poder llegar a una conclusión. Además, es imposible "poner puertas al campo" y pretender que los diseñadores de páginas web no incorporen las novedades que se van creando, por ejemplo el multimedia.

También se considera primordial que la actualización se realice de forma frecuente en los contenidos cambiantes, algo evidente si tratamos con información dinámica. Además, debe figurar en sitio visible la fecha de la última actualización de cada página, si bien por el momento no es un hábito muy extendido pues de las 16 webs seleccionadas sólo consta en seis.

Del estudio realizado en torno a los aspectos de accesibilidad a la información hay que decir que nos encontramos por debajo del $50 \%$ de satisfacción ya que no se cumplen los valores reseñados en la mitad de los sitios web, si bien hay que señalar que algunos puntos están bastante presentes, por ejemplo la disposición de guías de navegación - sea en forma de barras de opciones, en menús desplegables o mediante frames-y la elaboración de mapas del sitio. Otras recomenda- ciones se encuentran con algo menos de frecuencia pero empiezan a ser habituales: la colocación de la fecha de actualización en un lugar visible dentro de la web y la dirección de contacto del webmaster.

Algunos aspectos con menos presencia, pero que esperamos que se impongan, son la búsqueda rápida por palabras, la traducción a otras lenguas y la consideración hacia los discapacitados. Respecto a esta última alusión se está trabajando en distintas sedes web con el fin de adaptar las páginas a los lectores que utilizan las personas con problemas visuales en los ordenadores. Cantabria va a ser pionera desde principios de 2002 con sus adaptaciones para teclados Braille, sintetizadores de voz y programas de ampliación y contraste de caracteres. Por otro lado, y como iniciativa de acercamiento a los disminuidos psíquicos, también Cantabria dispone de símbolos Bliss en la mayoría de las páginas ${ }^{1}$.

\section{Conclusiones}

Parece claro que el objetivo de ofrecer información en la web es acercar el parlamento a la sociedad. Por lo tanto hay que pensar en un ciudadano "de la calle", que no conoce a la perfección el funcionamiento parlamentario ni necesariamente maneja con gran fluidez las herramientas de navegación. En consecuencia, tan importante será el contenido de estas páginas como la forma en que se le hace llegar. Por un lado es necesario mostrar las funciones de la cámara, los procedimientos y trámites parlamentarios y legislativos, el estado de cada iniciativa, etc. Por otro, resulta fundamental que la información se presente de una manera tan clara y sencilla que no suponga un gran esfuerzo de localización; esto se consigue con la inclusión en la página de inicio de las secciones en las que se divide el contenido: al menos información general, órganos y miembros parlamentarios, directorio de servicios, publicaciones, normas básicas y enlaces de interés.

En cuanto a su contenido informativo hay que decir que en general nuestros parlamentos aportan una gran variedad de datos en todos los aspectos analizados. Destacan el País Vasco evaluado con más de un 90\% seguido de Cataluña, Valencia y Aragón (entre un 75 y un $80 \%$ ). Se ha observado que la información acerca de los diversos órganos y miembros parlamentarios suele estar presente, al igual que las funciones y los textos normativos.

Otro aspecto que no se debe obviar en el diseño de información es la interacción del ciudadano con los órganos y miembros de la cámara. Este objetivo queda cubierto con la provisión de correo electrónico, buzones de participación y foros de discusión. Los parlamentos que han contemplado en mayor medida esta 
posibilidad de participación son en primer lugar el valenciano (más de un 80\%), Baleares y Cantabria (60\%), seguido de Andalucía y Cataluña (alrededor del $50 \%)$.

Si las páginas web deben facilitar el acceso a los contenidos, resulta básico contar con un mapa que profundice en los niveles suficientes para abarcar toda la información, así como un buscador interno que muestre al usuario las páginas que citan el tema de su interés. Ambos deberían estar disponibles al menos en la página de inicio.

Las sedes que mayor calificación han obtenido en este apartado son Cataluña con un $80 \%$, Andalucía, Castilla y León y Navarra con un $65 \%$ y Baleares con un $60 \%$.

La concienciación de los parlamentos autonómicos españoles en cuanto al aprovechamiento de las nuevas tecnologías les está llevando a una mejora continua de los contenidos y el diseño de las páginas web, y eso repercute sin duda en la calidad de nuestro sistema democrático; todo ello influirá en que se arbitren nuevos cauces de participación ciudadana en la vida parlamentaria potenciados por internet.

\section{Nota}

1. Sistema pictográfico de comunicación cuyos símbolos fueron creados por Karl Bliss y remiten directamente a significados en lugar de a fonemas.

\section{Bibliografía}

Aranda Torres, Patricio. "Las bibliotecas y los servicios de información parlamentarios como instrumentos para el desarrollo democrático". $65^{\text {th }}$ Ifla council and general conference, 1999.

http://www.ifla.org/ifla65/papers/070-101s.htm

Arterton, Christopher. Can technology protect democracy? Newbury Park: Sage, 1987.

Assemblée Parlementaire du Conseil de l'Europe. "Résolution 1.120 (1997) relative aux incidences des nouvelles technologies de communication et d'information sur la démocratie". 22 de abril de 1997.

Coleman, Stephen; Taylor, John; van de Donk, Wim. (eds.). Parliament in the age of the internet. Oxford: Oxford University Press, 1999.
Delgado Iribarren, Manuel. "Las nuevas tecnologías en la vida parlamentaria”. XX Jornadas universidad-parlamento (Logroño, 20-28 febrero 2001). En prensa.

Hjordtal, Helge M. "Rapport sur les technologies de l'information au sein des parlements". En: Informations constitutionelles et parlementaires, 1991, n. 161, pp. 1-35.

"Informe de la Comisión especial sobre redes informáticas". En: Boletín Oficial de las Cortes Generales. Senado, 1999, 27 de diciembre, n. 812.

Inter-parliamentary Council. Guidelines for the content and structure of parliamentary web sites.

http://www.ipu.org/cntr-e/web.pdf

López, Bernat. “Ciber... democràcia?”. En: [Democràcia web], 1998, junio, paper n. 2 .

http://www.democraciaweb.org/demoa.htm

Maciá, Mateo. "Sistemas de información parlamentaria y nuevas tecnologías". En: Revista de las Cortes Generales, 1993, n. 30, pp. 225-233.

Pau i Vall, Francesc; Picanyol, Jordi. "Democracia y nuevas tecnologías". Parlamento y sistema electoral: VI jornadas de la Asociación Española de Letrados de Parlamentos. Pamplona: Aranzadi, 1999.

Pau i Vall, Francesc. "Democracia e internet". En: Anuario de derecho constitucional y parlamentario, 1998, n. 10, pp. 195-213.

Ramos Vielba, Irene; Gonzalo, Miguel Ángel. "La documentación parlamentaria en internet I (el caso de la página web del Congreso de los Diputados de España)". En: Revista de las Cortes Generales, 2000, n. 50, pp. 305-327.

Ramos Vielba, Irene; Gonzalo, Miguel Ángel. "La documentación parlamentaria en internet II (el caso de la página web de las asambleas legislativas de las comunidades autónomas)". En: Revista de las Cortes Generales, 2000, n. 51, pp. 217-250.

Martínez Robledo, Josefa; Saorín, Tomás. "Contenidos y estrategias de diseño para webs de la Administración Pública”. En: Novática, 1997, n. 127 , pp. 35-38.

Stagliano, Riccardo. “Qu'est-ce qu'une démocratie électronique?”. En: [Democràcia web], 1998, mayo, paper n. 1.

http://www.democraciaweb.org/demoa.htm

Taylor, John A.; Burt, Eleanor. "Parliaments on the web: learning through innovation”. En: Parliamentary affairs, 1999, v. 52, n. 3, pp. 503517.

Mari Carmen Marcos; Ana Belén Gil mcmarcos@posta.unizar.es anagil27@hotmail.com

\section{Próximos números monográlicos}

